\title{
Conceptualizing Digital Transformation Project Effectiveness: A Review and Synthesis of the Literature
}

\author{
Daniel Lukito ${ }^{1,3, *}$, Suharnomo², and Mirwan S. Perdhana ${ }^{2}$ \\ ${ }^{1}$ Ph.D. Student. Doctorate Degree Program, Faculty of Economics and Business, Diponegoro University, \\ Semarang - 50241, Indonesia \\ ${ }^{2}$ Department of Management, Faculty of Economics and Business, Diponegoro University, Semarang - 50241, \\ Indonesia \\ ${ }^{3}$ Management Department, BINUS Online Learning, Bina Nusantara University, Jakarta - 11530, Indonesia
}

\begin{abstract}
Digital transformation has been a topic of interest in the last decade. However, the concept of digital transformation project effectiveness remains unclear. Many people view digital transformation as a never-ending process. Therefore, many researchers use digital maturity to predict whether an organization will be successful in its digital transformation. However, the fact that the never-ending digital transformation process is actually developed upon the continuous implementation of various digitalization projects should not be ignored. The effectiveness of each digital transformation project influences the success of the long journey of an organization's digital transformation. This article aims to provide a conceptualization of digital transformation project effectiveness as a multi-dimensional construct. This new conceptualization was developed based on the evidence found in the literature and the literature review synthesis. This study shows that the Digital Transformation Project Effectiveness has four dimensions: Business Performance, Financial Performance, Digitally Fit People, and Sustainable Competitiveness. To the best of our knowledge, we are the first to conceptualize the effectiveness of digital transformation as a short-term transformation project using the grounded theory method for a rigorous literature review. This study's findings are beneficial to both researchers and practitioners by giving more clarity and better comprehension regarding the concept of digital transformation project effectiveness, thus opening more room for further research and discussions.
\end{abstract}

Keywords: business performance; sustainable competitiveness; project success; coding analysis; grounded theory method

\section{Introduction}

Digital transformation has received enormous attention in the past decade. Many practitioners pursue the knowledge about this topic because they realize that in the near future, they must lead their organization in digital transformation efforts while recognizing the low rate of success experienced by various organizations (De la Boutetière, Montagner, \& Reich, 2018; Ellis \& Heneghan, 2017). The practitioners need much information about how other 
organizations carried out their digital transformation process and how well they performed. The practitioners need this information to increase the chances of their organizations' successful digital transformation. The need for knowledge and information has attracted researchers' interest to reveal various things related to digital transformation that can help practitioners achieve success. The word success itself is still a term with no specific definition; hence it is difficult to determine how it can be measured. Some researchers believe that digital transformation is not a process that has a finish line. Researchers consider digital transformation to be a continuous and endless process of change, as digital technology continues to evolve (Tadeu, Duarte, Taurion, \& Jamil, 2019, p. 9; Warner \& Wäger, 2019). New possibilities open whenever there is an advancement in recent technology; there are even possibilities to breakthrough into the next generation of technology (Harwood \& Eaves, 2020). Researchers developed the concept of digital maturity as a predictive measurement of digital transformation success (Kane, Palmer, Nguyen-Phillips, Kiron, \& Buckley, 2017). An organization is more likely to succeed in digital transformation if it was digitally maturing (Gurumurthy, Schatsky, \& Camhi, 2020; Mettler \& Pinto, 2018; Salviotti, Gaur, \& Pennarola, 2019).

The concept of measuring digital maturity as a measure of an organization's potential for success in its digital transformation process is interesting and logical. However, in an era when digital technology advances rapidly and in unpredictable directions, almost no strategy or business model can last for an extended period. The digital transformation is facing the same challenges. Despite being considered an endless process, organization leaders acknowledge that digital transformation consists of many digital initiatives or projects implemented and completed one by one (Kohnke, 2017). Practitioners and researchers often argue that organizational agility is a determinant of digital transformation success (Allen, 2019; Mugge, Abbu, Michaelis, Kwiatkowski, \& Gudergan, 2020; Tronvoll, Sklyar, Sörhammar, \& Kowalkowski, 2020). It means that the organizations need to be able to stop whatever they are doing quickly and get ready to change the course.

Organization leaders could never completely lock the choices within a large-scale project into a deterministic trajectory (Hetemi, Jerbrant, \& Mere, 2020). The strict and rigid system lacks flexibility and often becomes a challenge in a change process, for example, when the organization wants projects to have a shorter lead time (Whyte, Stasis, \& Lindkvist, 2016). An organization needs to adapt to the changes in market demands. There is a method called the agile management method. This method allows the organization to develop short-term projects; hence, it can complete them quickly. This method allows an organization to easily change its strategy and business model when needed to adapt to changing market demands (Carcary, Doherty, \& Conway, 2016). It can, indeed, take years to implement the whole digital transformation in an organization. However, an individual project may take only about 3-4 months (Keinz \& Marhold, 2020). Project management teams need to have clarity on evaluating individual projects, whether they are successful or not, for the whole project to be successful (Serra \& Kunc, 2015). Effectively carrying out short-term digital transformation projects is one of the keys to an organization's digital transformation success.

The digital transformation project effectiveness as a concept has a vital role in future research, especially among researchers seeking to find causal effects among the digital transformation model variables. However, it seems that only a few researchers give proper attention to the concept. An initial search in SCOPUS, Emerald, and Science Direct online databases using the keywords ("digital transformation" AND "project effectiveness") did not yield any documents meeting the keyword requirements. 
Discussions about how digital transformation affects other factors' effectiveness or other variables are more commonly found than how to measure the digital transformation project's effectiveness. For example, digital transformation can make companies more productive and cost-effective (Falcão, 2019; Lazaro-Aleman, Manrique-Galdos, Ramirez-Valdivia, Raymundo-Ibañez, \& Moguerza, 2020); digital transformation also makes collaboration among economic entities more effective (Frolov, Kaminchenko, Kovylkin, Popova, \& Pavlova, 2017); and it can affect the effectiveness of modern organizations (Tikhonov \& Novikov, 2020).

Kontić and Vidicki (2018) conducted research to test the measurement tool for digital transformation. However, instead of digital transformation, they used the measurement tool for digital maturity developed by Bonnet, Puram, Buvat, Kanakadandi, and Khadikar (2015). They measured the conditions required for a successful digital transformation instead of measuring the digital transformation's effectiveness. These various papers show a lack of clarity and comprehension regarding the concept of digital transformation project effectiveness and how to measure it.

Many researchers have studied digital transformation. However, to the best of our knowledge, we are the first to conceptualize the effectiveness of digital transformation as a single, short-term transformation project using the grounded theory method for rigorously reviewing the literature. This new conceptualization was developed based on the literature's evidence and the synthesis of the literature. This study is the first part of a more extensive study seeking to answer the research question, "How do we measure digital transformation project effectiveness?" By itself, the study in this paper aims to answer the research question, "What is the construct of digital transformation project effectiveness?"

\section{Methodology}

To assess digital transformation project effectiveness, one must compare the results against the purposes that drive an organization to implement a particular digital transformation project in the first place. Different organizations may have different reasons to implement digital transformation. However, we believe that some similar purposes drive most organizations to implement digital transformation. These purposes are usually things or objectives that are considered as benefits to the organization. Therefore, finding these general purposes can be done by reviewing existing works that mention the objectives or benefits of digital transformation for organizations. We understand that the findings might not apply to all organizations. Non-profit organizations or government organizations may have different objectives than entrepreneurial organizations. However, it is also believed that some perceived benefits are still shared among them.

This paper used the guidance to use grounded theory to rigorously reviewing the literature written by Wolfswinkel, Furtmueller, and Wilderom (2013) to find a higher-order organization's purpose. They proposed five stages, which were 1. Define; 2. Search, 3. Select, 4. Analyze, 5. Present. The 5th stage, 'Present,' can be found in the Results and Discussion part of this paper.

\subsection{Define}

The inclusion and exclusion criteria in the data set need to be defined in order to perform a systematic literature search efficiently. The first thing to do is framing the scope of the review and selecting the criteria to be included or excluded (Wolfswinkel et al., 2013) need to be framed. Setting the review's boundaries requires defining several criteria for inclusion and 
exclusion of sources, the appropriate fields of research, relevant sources, and the criteria to identify and retrieve those sources (Vial, 2019).

For the current study, we initially decided to select and review only the peer-reviewed works. Therefore, we browsed for peer-reviewed journal articles and conference proceedings within the Scopus online database. We chose the Scopus online database because it is reputed to be the largest abstract and citation database of peer-reviewed literature for scientific journals, books, and conference proceedings (Scopus, 2020). In reality, our initial search in the Scopus online database with the search query syntax TITLE-ABS-KEY ("digital transformation" AND "project effectiveness") returned zero documents. We used the same search query syntax in the Emerald and Science Direct online database and found the same results. We then decided to try two things. First, we changed the keywords to use synonyms. Second, due to the scarcity of the literature that fits our purpose for this study, we also reviewed the non-peer-reviewed works.

Setting the language boundary, we would only review the works of literature written in English. The English language is the only one chosen due to our limitations in other languages. Setting the field of research boundary, we would only review the literature in the field of digital transformation. The keywords for the search must contain the term "digital transformation."

The concept of digital transformation project effectiveness in this study is built on the idea that project effectiveness is measured by comparing the project results against the purposes determined before it is executed. The purposes themselves can be whatever objectives or benefits are expected by the organization. Every organization has a foundational drive to gain from opportunities; therefore, there is a need for requiring a beneficial change that becomes a solution in a given situation (Di Muro \& Turner, 2018). Some objectives of digital transformation may include economic benefits, improving the quality of results, reducing work effort related to the complexity of tasks and documentation, as well as technology acceptance, an equal knowledge base among workers, and improving work-life balance (Hildebrandt, Kluge, \& Ziefle, 2020).

We used the keywords "benefits of digital transformation" when searching in the Scopus database. This time the search resulted in nine documents, a number we deemed insufficient. We realized that we had to go beyond peer-reviewed literature and decided to search the Google Scholar database. We decided to go with a constrained keyword set since the Google Scholar database is much larger than Scopus. We used ("Digital Transformation" + "measurement" + "project effectiveness") as the keywords. This search resulted in 14 documents.

\subsection{Search}

The next step was to retrieve the documents. These various articles can be obtained from the Scopus database and various other sources in cyberspace. We managed to retrieve 19 out of 23 documents, resulting in an $82.6 \%$ retrieval rate.

\subsection{Selection}

We then read the retrieved literature and ascertained its relevance with the current study. Each of the 19 documents retrieved contributed to the study. We also read the abstracts of the four pieces of literature that could not be retrieved. There were some valuable sentences within the abstracts of three out of four of the documents. We then found two additional articles within a journal where one of the retrieved articles was published. After we retrieved and read both documents, we decided to add them to this study's literature review dataset, ending with a total of 24 documents. 


\subsection{Analyze}

We analyzed and coded the 24 documents. We tried to find the critical words or sentences that showed the organization's benefits or digital transformation objectives in the open coding stage. We grouped the open coding stage findings into several categories in the axial coding stage and named those categories. When there is a code that does not suitable for any other group, we allow it to form its own category. The names given to the categories can be new words or words already in open coding analysis findings. We decided to use names that can represent each group. In the selective coding stage, the various categories formed in the axial coding analysis were grouped into several main categories. We also assigned new names to these main categories accordingly.

\section{Results and Discussion}

In the open coding stage, we identified 67 objectives or the expected benefits of digital transformation. These objectives or benefits were then grouped into 15 categories in the axial coding process. The selective coding process generated four main categories showing more clearly the intended purpose of digital transformation. The four main categories are Business Performance, Technology Performance, Digitally Fit People, and Sustainable Competitiveness. The expected benefits of digital transformation projects found in this study can be viewed in Fig.1.

\section{Business Performance}

The effectiveness of digital transformation projects related to Business Performance can be measured based on whether the results of the digital transformation project, related to cost reduction (Kuntsman \& Arenkov, 2019; Vasilev et al., 2020), revenue growth (Alrawadieh et al., 2020; Kohl \& Bryant, 2017), market share (Wolff \& Nuseibah, 2017), and market size (Lappi \& Aaltonen, 2017) meet the initial expectations. The names we chose for the subcategories and the main category in the first dimension tended to be more suitable for profitoriented organizations and for not-for-profit organizations that need to support themselves financially. When applied to non-profit organizations, this main category is more suitable to be called Operational Performance, where the main objective is limited to reducing costs and expanding service coverage.

Fig. 1: The expected benefits of a digital transformation project

\begin{tabular}{|l|l|}
\hline $\begin{array}{l}\text { Business Performance: } \\
\text { Cost reduction } \\
\text { Revenue Growth } \\
\text { Market share } \\
\text { Market size }\end{array}$ & $\begin{array}{l}\text { Technology Performance: } \\
\text { Function fit } \\
\text { Usefulness } \\
\text { Cyber Security }\end{array}$ \\
\hline $\begin{array}{l}|c| \\
\text { The Expected Benefits of } \\
\text { Sugital Transformation Project }\end{array}$ \\
$\begin{array}{l}\text { Sigitally capable } \\
\text { Attracts digital talents } \\
\text { Digitally fit leaders }\end{array}$ & $\begin{array}{l}\text { Sustainable Competitiveness: } \\
\text { Digital Customer Relationship } \\
\text { New Business Model Generation } \\
\text { Digital Capabilities Growth } \\
\text { Continuous Improvement }\end{array}$ \\
\hline
\end{tabular}




\section{Technology Performance}

Organizations can achieve more extraordinary performance by adopting new technology (Büchi, Cugno, \& Castagnoli, 2020). The heterogeneity of organizations demands different innovators that lead to various technological innovations (Hervas-Oliver, Sempere-Ripoll, \& Boronat-Moll, 2021). The results of project implementation need to be compared with organizational expectations regarding the technology itself. Three things indicate the performance of the technology. First, whether the functions, features, or infrastructure of the implemented technology complies with what is promised (Gubernatorov et al., 2019, p. 640). The implemented technology can comply with the demand but may or may not deliver the benefits as expected. Therefore, the second indicator is whether the implemented technology can deliver results as expected (Tesařová et al., 2020). Third, related to information security, the data must be protected and not used for purposes other than what has been agreed to by data owners (Che \& Bao, 2019).

\section{Digitally Fit People}

Every digital transformation project needs supportive people willing to change according to the digital transformation project's requirements (Knapp, 2018; Prioteasa et al., 2020). Without the support of all those affected by the change, the project cannot run as expected. The organization also needs its members to build expertise in operating the new technology (Wolff \& Nuseibah, 2017). Significant changes driven by applying new technologies and process transformation are expected at work. Therefore, organizations demand new competencies from employees using new production systems (Horváth \& Szabó, 2019). When an organization is known to have sophisticated technologies and competent people who can utilize these technologies, it will attract more prospective talents with adequate digital skills (Wolff \& Nuseibah, 2017). Finally, the organization also expected the emergence of leaders within the organizational management who understand their duties in the digital transformation process and have the ability to oversee the entire project (Burton-Jones et al., 2020; Cruz \& ONeill, 2018).

\section{Sustainable Competitiveness}

Most organizations or companies undergo digital transformation because they do not want to lose their existence. In addition to trying to survive digital disruption from emerging new competitors, they also have to survive other competitors who use more traditional methods. This study's results suggest four things that can be done to maintain or even improve organizational competitiveness. First, developing various activities facilitates interactions and enhances relationships with customers using digital technology (Kohl \& Bryant, 2017; Kuntsman \& Arenkov, 2019). Second, it encourages the company's innovative spirit to develop new solutions and new products to offer customers that simultaneously create new business models based on digital technology (Borowiecki et al., 2019; Leischnig et al., 2017). Third, implemented technology may change rapidly. These changes force the organization to redevelop all the affected human resources' digital capabilities to master the new technology (Eden et al., 2019). Fourth, the organization needs to ensure that it can continue to be relevant from time to time (Yucel, 2018). Risk assessment and risk management need to be carried out regularly to improve the prevailing operational standards and continuously build higher competencies. The key to maintaining competitiveness is to practice the continuous improvement method. 
Fig. 2: Conceptual Construct of Digital Transformation Project Effectiveness

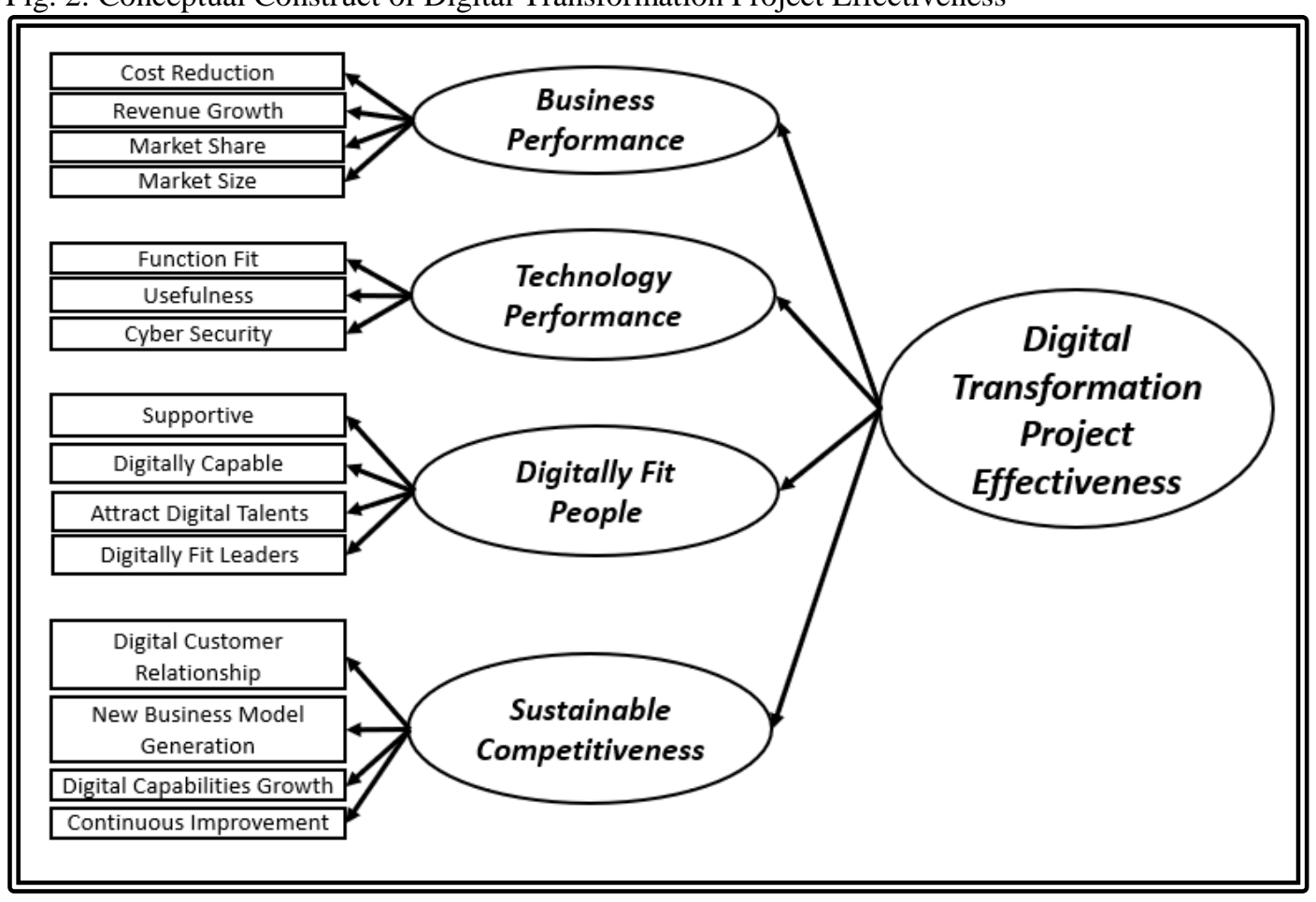

The conceptual construct of Digital Transformation Project Effectiveness as the result of this study can be found in Figure 2. The conceptualization of digital transformation project effectiveness developed in this study is different from the concept of digital maturity developed by Bonnet et al. (2015). which also has four dimensions, namely (a) Digital-First Mindset, (b) Digitized Practices, (c) Empowered Talent, and (d) Data Access and Collaboration Tools. The concept of digital maturity emerges from various factors that researchers considered to enable the digital transformation process. In contrast, the concept of digital transformation project effectiveness refers to how well the project results meet organization leaders' expectations. We can also find similar differences when comparing the concept of digital transformation project effectiveness to the Digital Transformation Scoreboard, which has five dimensions, namely (a) Digital Infrastructure, (b) Investment and Access to Finance, (c) Supply and Demand of Digital Skills, (d) e-Leadership, and (e) Entrepreneurial Culture (Marolt, Pucihar, Lenart, \& Vidmar, 2019).

\section{Conclusions}

We successfully developed a conceptual construct of a digital transformation project's effectiveness using a grounded theory method to conduct a rigorous literature review. Thus, providing an answer to the research question, "what is the construct of digital transformation project effectiveness?" Digital transformation project effectiveness has four dimensions: Business Performance, Technology Performance, Digitally Fit People, and Sustainable Competitiveness.

This study's results show that the concept of digital transformation project effectiveness differs from digital maturity. While other researchers focus more on the process or the enabler when measuring digital transformation, digital transformation project effectiveness focuses on the outcome. 
Our study contributes to the body of knowledge about digital transformation by conceptualizing its project effectiveness. The findings generated by this study are beneficial to both researchers and practitioners by giving more clarity and better comprehension regarding the concept of digital transformation project effectiveness. Our study opens room for future research and discussions on the topic of digital transformation, especially surrounding its effectiveness. The conceptual construct of digital transformation project effectiveness will be useful in both qualitative and quantitative research.

\section{Limitations and suggestions for future research}

This research has several limitations. First, we were limited by an inability to retrieve some of the literature; consequently, we could not review those literature. Second, there are still very few causal researches on the topic of digital transformation; thus, fewer papers can be found studying the variables that impact its success or effectiveness. Third, the study does not differentiate the objectives or benefits between a non-profit organization and a for-profit organization. A comparison study for the two organization types will be a valuable addition to the concept. Fourth, the study mainly used the deductive method based on an extensive literature review. A complementary inductive method based on qualitative information will refine the current findings.

A further study on the scale development of digital transformation project effectiveness is required. Future research studies investigating causal relationships between digital transformation project effectiveness and other variables are wide open.

\section{Acknowledgment}

The authors would like to thank Prof.Dr. Dra. Naili Farida, M.Si., for reviewing the draft of this paper and giving valuable feedback.

\section{References}

Allen, R. (2019). Transformational and digital change: a UK perspective. Organisational Social Dynamics, 19(2), 143-167. doi:10.33212/osd.v19n2.2019.143

Alrawadieh, Z., Alrawadieh, Z., \& Cetin, G. (2020). Digital transformation and revenue management: Evidence from the hotel industry. Tourism Economics, 1-18. doi:10.1177/1354816620901928

Bonnet, D., Puram, A. D., Buvat, J., Kanakadandi, S., \& Khadikar, A. (2015). Organizing for digital: Why digital dexterity matters. Capgemini Consulting.

Borowiecki, M., Machado, D., Paunov, C., \& Planes-Satorra, S. (2019). Supporting research for sustainable development. OECD Science, Technology and Industry Policy(78). doi:https://doi.org/10.1787/6c9b7be4-en

Büchi, G., Cugno, M., \& Castagnoli, R. (2020). Smart factory performance and Industry 4.0. Technological Forecasting and Social Change, 150, 119790. doi:https://doi.org/10.1016/j.techfore.2019.119790

Burton-Jones, A., Akhlaghpour, S., Ayre, S., Barde, P., Staib, A., \& Sullivan, C. (2020). Changing the conversation on evaluating digital transformation in healthcare: Insights from an institutional analysis. Information Organization, 30(1), 100255. doi:https://doi.org/10.1016/j.infoandorg.2019.100255 
Carcary, M., Doherty, E., \& Conway, G. (2016). A dynamic capability approach to digital transformation: a focus on key foundational themes. Paper presented at The European Conference on Information Systems Management.

Che, G., \& Bao, H. (2019). Government Information System Audit Should Focus on Egovernment. Paper presented at the 2nd International Seminar on Education Research and Social Science (ISERSS 2019).

Cruz, A. T., \& ONeill, H. (2018). Digital Transformation in the Healthcare SectorInnovation in the Purchasing Process. Paper presented at the 18th Conference of the Portuguese Information Systems Association, Portugal.

De la Boutetière, H., Montagner, A., \& Reich, A. (2018). Unlocking success in digital transformations. Retrieved from https://www.mckinsey.com/businessfunctions/organization/our-insights/unlocking-success-in-digital-transformations\#

Di Muro, P., \& Turner, J. R. (2018). Entrepreneurial opportunity pursuit through business model transformation: a project perspective. International Journal of Project Management, 36(7), 968-979. doi:https://doi.org/10.1016/j.ijproman.2018.07.001

Eden, R., Burton-Jones, A., Grant, J., Staib, A., \& Sullivan, C. (2019). Digitising an Australian university hospital: Qualitative analysis of staff-reported impact. Australian Health Review. doi:10.1071/AH18218

Ellis, A., \& Heneghan, L. (2017). Navigating Uncertainty. Retrieved from https://assets.kpmg/content/dam/kpmg/xx/pdf/2017/07/harvey-nash-kpmg-cio-survey2017.pdf

Falcão, R. A. (2019). Generation of Business in SMEs through Digital Transformation with Local Productive Arrangement of Information Technologies. Paper presented at the CAPSI 2019 Proceedings.

Frolov, V. G., Kaminchenko, D. I., Kovylkin, D. Y., Popova, J. A., \& Pavlova, A. A. (2017). The main economic factors of sustainable manufacturing within the industrial policy concept of industry 4.0. Academy of Strategic Management Journal, 16(Special issue 2).

Gubernatorov, A. M., Stelmashenko, N. D., Ulanov, E. A., Chekushov, A. A., \& Mayorov, Y. N. (2019). Development of the Mechanism of Formation of Effective Digital Platform in the Glass Industry and Estimation of the Efficiency of Its Realization. Paper presented at the Institute of Scientific Communications Conference.

Gurumurthy, R., Schatsky, D., \& Camhi, J. (2020). Uncovering the connection between digital maturity and financial performance. Retrieved from https://www2.deloitte.com/us/en/insights/topics/digital-transformation/digitaltransformation-survey.html

Harwood, S., \& Eaves, S. (2020). Conceptualising technology, its development and future: The six genres of technology. Technological Forecasting and Social Change, 160, 120174. doi:https://doi.org/10.1016/j.techfore.2020.120174

Hervas-Oliver, J.-L., Sempere-Ripoll, F., \& Boronat-Moll, C. (2021). Technological innovation typologies and open innovation in SMEs: Beyond internal and external sources of knowledge. Technological Forecasting and Social Change, 162, 120338. doi:https://doi.org/10.1016/j.techfore.2020.120338

Hetemi, E., Jerbrant, A., \& Mere, J. O. (2020). Exploring the emergence of lock-in in largescale projects: A process view. International Journal of Project Management, 38, 47 63. doi:https://doi.org/10.1016/j.ijproman.2019.10.001 
Hildebrandt, J., Kluge, J., \& Ziefle, M. (2020). A Successful Transformation of Work? An Exploratory Analysis on Requirements and Evaluation Criteria. Paper presented at the International Conference on Human-Computer Interaction.

Horváth, D., \& Szabó, R. Z. (2019). Driving forces and barriers of Industry 4.0: Do multinational and small and medium-sized companies have equal opportunities? Technological Forecasting and Social Change, 146, 119-132. doi:https://doi.org/10.1016/j.techfore.2019.05.021

Kane, G. C., Palmer, D., Nguyen-Phillips, A., Kiron, D., \& Buckley, N. (2017). Achieving digital maturity. MIT Sloan Management Review, 59(1).

Keinz, P., \& Marhold, K. (2020). Technological competence leveraging projects via intermediaries: Viable means to outbound open innovation and mediated capability building? International Journal of Project Management. doi:https://doi.org/10.1016/j.ijproman.2020.10.006

Knapp, M. (2018). Portfolios and Governance. In Enterprise Portfolio Governance (pp. 3788): Springer.

Kohl, R., \& Bryant, C. (2017). Defining Digital Transformation Success Metrics. www.gorillagroup.com/wp-content/uploads/2017/08/Digital-SuccessMetrics_Gorilla-Group-1.pdf

Kohnke, O. (2017). It's not just about technology: the people side of digitization. In Shaping the digital enterprise (pp. 69-91): Springer.

Kontić, L., \& Vidicki, Đ. (2018). Strategy for digital organization: Testing a measurement tool for digital transformation. Strategic Management Journal, 23(1), 29-35. doi:10.5937/StraMan1801029K

Kuntsman, A., \& Arenkov, I. A. (2019). Method for Assessing Effectiveness of Company Digital Transformation: Integrated approach. IBIMA Business Review, 2019, 1-16. doi: $10.5171 / 2019.334457$

Lappi, T., \& Aaltonen, K. (2017). Project governance in public sector agile software projects. International Journal of Managing Projects in Business. doi:10.1108/IJMPB-042016-0031

Lazaro-Aleman, W., Manrique-Galdos, F., Ramirez-Valdivia, C., Raymundo-Ibañez, C., \& Moguerza, J. M. (2020). Digital Transformation Model for the Reduction of Time Taken for Document Management with a Technology Adoption Approach for Construction SMEs. Paper presented at the 2020 9th International Conference on Industrial Technology and Management (ICITM).

Leischnig, A., Ivens, B. S., \& Kammerlander, N. (2017). A new conceptual lens for marketing: a configurational perspective based on the business model concept. AMS Review, 7(3-4), 138-153. doi:https://doi.org/10.1007/s13162-017-0107-6

Marolt, M., Pucihar, A., Lenart, G., \& Vidmar, D. (2019). Digital transformation scoreboard-Case of Slovenia and Croatia. Paper presented at the 2019 42nd International Convention on Information and Communication Technology, Electronics and Microelectronics (MIPRO).

Mettler, T., \& Pinto, R. (2018). Evolutionary paths and influencing factors towards digital maturity: An analysis of the status quo in Swiss hospitals. Technological Forecasting and Social Change, 133, 104-117. doi:https://doi.org/10.1016/j.techfore.2018.03.009

Mugge, P., Abbu, H., Michaelis, T. L., Kwiatkowski, A., \& Gudergan, G. (2020). Patterns of Digitization: A Practical Guide to Digital Transformation. Research-Technology Management, 63(2), 27-35. doi:10.1080/08956308.2020.1707003 
Ossewaarde, M (2019). Digital transformation and the renewal of social theory: Unpacking the new fraudulent myths and misplaced metaphors. Technological Forecasting and Social Change, 146, 24-30. doi: 10.1016/j.techfore.2019.05.007

Prioteasa, A.-L., Chicu, N., \& Ciocoiu, C. N. (2020). Implications of digitization on risk management in Romanian companies. Paper presented at the Proceedings of the $31 \mathrm{st}$ International Business Information Management Association Conference, IBIMA 2018: Innovation Management and Education Excellence through Vision 2020.

Salviotti, G., Gaur, A., \& Pennarola, F. (2019). Strategic Factors Enabling Digital Maturity: An Extended Survey.

Scopus. (2020, April 29th, 2020). What is Scopus Preview? Retrieved from https://service.elsevier.com/app/answers/detail/a_id/15534/supporthub/scopus/\#tips

Serra, C. E. M., \& Kunc, M. (2015). Benefits Realisation Management and its influence on project success and on the execution of business strategies. International Journal of Project Management, 33, 53-66. doi:http://dx.doi.org/10.1016/j.ijproman.2014.03.011

Tadeu, H. F. B., Duarte, A. L. d. C. M., Taurion, C., \& Jamil, G. L. (2019). Digital Transformation: Digital Maturity Applied to Study Brazilian Perspective for Industry 4.0. In Best Practices in Manufacturing Processes (pp. 3-27): Springer.

Tesařová, M., Krmela, A., \& Šimberová, I. (2020). Digital support to external sustainability communication in self-adhesive labelling industry. Entrepreneurship Sustainability Issues, 7(3), 2109-2125. doi:10.9770/jesi.2020.7.3(44)

Tikhonov, A., \& Novikov, S. (2020). Modern Organization Effective Functioning Evaluation. Quality-Access to Success, 21(178).

Tronvoll, B., Sklyar, A., Sörhammar, D., \& Kowalkowski, C. (2020). Transformational shifts through digital servitization. Industrial Marketing Management, 89(August 2020). doi:https://doi.org/10.1016/j.indmarman.2020.02.005

Utomo, R. G. P., Jasfar, F., \& Hadi, H. (2018). The Effect of Project-Based Organizational Learning Capability and Dynamic Environment on Project Portfolio Management Capability and Their Implication on Project Capability. International Journal of Creative Research and Studies, 2(12).

Vasilev, V. L., Gapsalamov, A. R., Akhmetshin, E. M., Bochkareva, T. N., Yumashev, A. V., \& Anisimova, T. I. (2020). Digitalization peculiarities of organizations: a case study. Entrepreneurship and Sustainability Issues, 7(4), 3173-3190. doi:10.9770/jesi.2020.7.4(39)

Vial, G. (2019). Understanding digital transformation: A review and a research agenda. The Journal of Strategic Information Systems, 28, 118-144. doi:https://doi.org/10.1016/j.jsis.2019.01.003

Warner, K. S., \& Wäger, M. (2019). Building dynamic capabilities for digital transformation: An ongoing process of strategic renewal. Long Range Planning, 52(3), 326-349. doi:https://doi.org/10.1016/j.lrp.2018.12.001

Whyte, J., Stasis, A., \& Lindkvist, C. (2016). Managing change in the delivery of complex projects: Configuration management, asset information and 'big data'. International Journal of Project Management, 34, 339-351. doi:10.1016/j.ijproman.2015.02.006

Wolff, C., \& Nuseibah, A. (2017). A projectized path towards an effective industryuniversity-cluster: Ruhrvalley. Paper presented at the 12th International Scientific and Technical Conference on Computer Sciences and Information Technologies (CSIT). 
Wolfswinkel, J. F., Furtmueller, E., \& Wilderom, C. P. (2013). Using grounded theory as a method for rigorously reviewing literature. European Journal of Information Systems, 22(1), 45-55. doi:10.1057/ejis.2011.51

Yucel, S. (2018). Estimating the Benefits, Drawbacks and Risk of Digital Transformation Strategy. Paper presented at the 2018 International Conference on Computational Science and Computational Intelligence (CSCI), Las Vegas, NV, USA. 